\title{
Cognitive Profile of Patients with Thalamic Hemorrhage according to Lesion Localization
}

\author{
Musa Temel $^{\mathrm{a}}$ Busra S.A. Polat ${ }^{\mathrm{b}}$ Nuriye Kayali ${ }^{\mathrm{b}}$ Omer Karadas ${ }^{\mathrm{c}}$ \\ a Sanliurfa Training and Research Hospital, Sanlıurfa, Turkey; ${ }^{\mathrm{b}}$ Gulhane Training and Research Hospital, Ankara, \\ Turkey; ${ }^{C}$ University of Health Sciences, Gulhane School of Medicine, Ankara, Turkey
}

\section{Keywords}

Thalamus · Cognition · Hemorrhage $\cdot$ Neuropsychological tests · Assessment

\begin{abstract}
Background: The thalamus is known as the central sensory and motor relay station of the brain generally. However, cognitive decline due to thalamic lesions has been previously reported in different studies. Also, it has been observed that different cognitive subdomains are affected according to the localization of the lesion in the thalamus. Objectives and Methods: Detailed neurophysiological tests were performed on 28 patients with thalamic hemorrhage and the control group. Patients were grouped according to lesion localization. The results were compared with both the control group and the hemorrhage groups themselves. Results: The performance of patients in all neuropsychological tests was significantly worse than that of the control group. Of the 28 patients, 15 had anterolateral, 5 had posterolateral, 5 had dorsal, and 3 had an anteromedial thalamic hemorrhage. The anteromedial group had the worst scores of almost all tests. Also, 2 situations came to notice in these tests. First, the posterolateral group achieved a remarkably low mean in the recall subgroup of the MMSE tests and verbal memory process tests. Second, the anterolateral group was found to
\end{abstract}

karger@karger.com www.karger.com/dee

Karger!"

GOPEN ACCESS
C 2021 The Author(s)

Published by S. Karger AG, Basel

This is an Open Access article licensed under the Creative Commons Attribution-NonCommercial-4.0 International License (CC BY-NC) (http://www.karger.com/Services/OpenAccessLicense), applicable to the online version of the article only. Usage and distribution for commercial purposes requires written permission. have a low mean in both the language subgroup of the MMSE tests and the phonemic subgroup of the verbal fluency tests. Conclusion: It was concluded in this study that thalamic hemorrhages affect cognition entirely regardless of the lesion localization. It was also observed that the lateral part of the thalamus was associated with language, the posterior part with memory, and the anteromedial part with the rest of the cognitive subdomains.

(C) 2021 The Author(s)

Published by S. Karger AG, Basel

\section{Introduction}

The thalamus is a complex structure consisting entirely of nuclei, located in the diencephalon at the brain stem's dorsal side. It is divided into 2 symmetrical parts by the third ventricle [1]. The Y-shaped lamina medullaris interna, located vertically in the thalamus, divides it into 3 parts; anterior, lateral, and medial. The thalamus is known as the brain's central sensory and motor relay station. It communicates and relays signals between subcortical and cerebellar regions and the cortex, playing a role in sleep, arousal, and primary sensory processing [2].

This study was conducted in Gulhane Training and Research Hospital.
Correspondence to:

Musa Temel, mdmusatemel@hotmail.com 
Intracerebral hemorrhages account for $10-20 \%$ of all strokes. $15-20 \%$ of these hemorrhages occur in the thalamus [3]. Cognitive decline due to thalamic lesions has been previously reported in different case studies [4-11]. Also, recently, the effects of the thalamus on cognitive functions have been demonstrated by various methods, such as functional magnetic resonance imaging and diffusion tensor imaging [12].

It has been observed that different cognitive subdomains are affected according to the localization of the lesion in the thalamus. Although cognitive dysfunction in patients with thalamic ischemia has been shown, the number of cases is deficient in thalamus hemorrhage patients. To the best of our knowledge, no controlled study has evaluated the cognitive dysfunction and depression in this group. Thus, in this study, we set out to assess the cognitive profiles of patients with thalamic hemorrhage, comparing them with a control group.

\section{Materials and Methods}

\section{Participants}

Twenty-eight patients admitted to the inpatient clinic of the Department of Neurology between 2016 and 2020 with the diagnosis of thalamic hemorrhage were included in this study. None of them had a dementia history or any medication associated with cognitive impairment. Patients with a severe motor disability or a systemic disease that may affect cognition other than thalamic hemorrhage were excluded from the study. The patients were evaluated within 3-6 months after the first event. Demographic and disease-specific data, including age, gender, and educational status of the patients and controls, were collected.

Local Ethics Committee approval from Gulhane Training and Research Hospital was obtained (Reference No. 19/233). Informed consent was obtained from the patients.

\section{Clinical Diagnosis}

All patients underwent uniform clinical assessment consisting of neurological examination, neuropsychological testing, and computed tomography (CT). CT images were obtained with the Toshiba (Aquilion One) device in $0.5-\mathrm{mm}$ sections. It was observed that hemorrhage was completely resolved at the assessment time.

CT images were evaluated with an experienced neuroradiologist, and thalamic hemorrhages were determined in 4 groups as anteromedial, anterolateral, posterolateral, and dorsal hemorrhages.

\section{Neuropsychological Assessment}

An experienced psychologist performed neuropsychological tests, and the psychologist did not know about the participant's group and the lesion location. The patients' and controls' global cognitive performance was evaluated using the Turkish version of the Mini-Mental State Examination (MMSE) [13].

Additional detailed neuropsychological tests were performed to evaluate the following domains: (1) memory (verbal memory
Table 1. Mean values of total MMSE and subgroup scores

\begin{tabular}{lccr}
\hline & Patients & Controls & $p$ value \\
\hline Total MMSE score & $22.64 \pm 5.2$ & $28.21 \pm 2.6$ & $<0.001$ \\
Orientation & $8.71 \pm 1.69$ & $9.89 \pm 0.41$ & $<0.001$ \\
Attention/calculation & $2.25 \pm 1.85$ & $4.15 \pm 1.03$ & $<0.001$ \\
Recall & $1.43 \pm 1.03$ & $2.36 \pm 0.67$ & 0.001 \\
Language & $7.18 \pm 1.90$ & $8.86 \pm 0.44$ & $<0.001$ \\
\hline
\end{tabular}

Values are means \pm standard deviations. Significant at $p<0.05$.

process test [14]), (2) attention (digit span tests [15]), (3) language, perseverance, and sustained attention (verbal fluency tests [16]), (4) executive functions (trail-making tests [17]), and (5) visuoconstruction, sequencing, and planning (clock-drawing test [18]).

The Geriatric Depression Scale [19] for patients over the age of 65 years and the Beck Depression Scale [20] for patients under the age of 65 years were used to evaluate the participants' emotional state.

\section{Statistical Analysis}

Descriptive statistics were expressed as mean, standard deviation, median, minimum, and maximum for continuous data and as count and proportion for categorical data. The statistical differences were calculated using the $\chi^{2}$ test for nominal variables. The distribution normality of the continuous variables was calculated with the Shapiro-Wilk test. Two groups were compared with the independent samples $t$ test for the normally distributed variables and the Mann-Whitney $U$ test for the nonnormally distributed variables.

Statistical analyses were performed using the IBM SPSS version 24 for Windows software and were reported with $95 \%$ confidence intervals. Values of $p<0.05$ were considered significant.

\section{Results}

Twenty-eight patients (18 males [64\%] and 10 females [36\%], mean age $60.75 \pm 9.61$ years, mean education 8.68 \pm 3.8 years) with thalamic hemorrhage and 28 controls (18 males and 10 females, mean age $60.89 \pm 9.57$ years, mean education $8.68 \pm 3.8$ years) were included. No significant differences were found for age and education levels between the groups ( $p=0.95$ and $p=1.00$, respectively).

Of the 28 patients, 15 had an anterolateral, 5 had a posterolateral, 5 had a dorsal, and 3 had an anteromedial thalamic hemorrhage. In the neurological examination, mild hemiparesis was determined in 6 patients (all had lateral thalamic hemorrhage) and varying hemisensorial impairment in 10 patients.

Regarding the MMSE, the performance of patients was significantly worse than that of the control group $(p<$ 
0.001; Table 1). Additionally, scores of other neuropsychological tests in patients were lower than in controls (Table 2).

The patients had more moderate-severe depressive symptoms than the control group $(p=0.013)$. Also, it was noticed that patients with anterolateral and posterolateral thalamic hemorrhage had more moderate-severe depressive features.

Due to the insufficient number of patients and the difference in numbers between the subgroups ( 3 of them had anteromedial and 15 of them had anterolateral hemorrhage), no statistical evaluation could be made to compare the relationship between the anatomical localization of the hemorrhage and the affected cognitive functions' subdomain. Thus, the results were evaluated only with respect to the scores of the tests. The neuropsychological test results, according to the localization of lesions, are shown in Table 3.

Two situations came to notice in these tests. First, the posterolateral group achieved a remarkably low mean in the recall subgroup of the MMSE tests and verbal memory process tests. Second, the anterolateral group was found to have a low mean in both the language subgroup of the MMSE tests and the phonemic subgroup of the verbal fluency tests. But this group had the highest mean in the semantic fluency test.

\section{Discussion}

Our study results showed that patients with thalamic hemorrhage performed worse than controls in all neuropsychological tests. Notably, according to the lesion's localization, the patients with anteromedial thalamic hemorrhage had lower scores than other groups.

In a recent review, it has been shown that patients with vascular syndrome of the thalamus had cognitive impairment in subdomains such as attention, orientation, memory, praxis, executive functions, concentration, global intellectual functions, behavior, and mood [21]. In another study, neuropsychological tests were performed on healthy people, and their thalamic volume was evaluated by magnetic resonance imaging [22]. It was reported that patients with low thalamic volumes obtained less successful results in neuropsychological tests. These results, which are similar to ours, showed that thalamic hemorrhages affect all domains of cognition.

It has been observed that memory, attention, and orientation were affected in a case with anterior thalamic infarction [4]. Additionally, memory impairment and

To Determine the Cognitive Subgroup

Associated with the Thalamus
Table 2. Results of the neuropsychological tests

\begin{tabular}{lccr}
\hline \multirow{2}{*}{ Tests } & Patients & \multicolumn{1}{l}{ Controls } & $p$ value \\
\hline Verbal memory process test & & \\
Immediate memory & $7.46 \pm 2.78$ & $11.07 \pm 2.01$ & $<0.001$ \\
Best learning & $8.29 \pm 1.86$ & $9.82 \pm 0.47$ & $<0.001$ \\
Delayed recall & $5 \pm 3.63$ & $9.68 \pm 2.43$ & $<0.001$ \\
Total recall & $10 \pm 3.82$ & $14.11 \pm 0.99$ & $<0.001$ \\
Verbal fluency test & & & \\
Phonemic & $6.71 \pm 4.52$ & $15.54 \pm 4.78$ & $<0.001$ \\
Semantic & $11.89 \pm 4.64$ & $24.11 \pm 5.65$ & $<0.001$ \\
Digit span test & & & \\
Forward & $4.57 \pm 0.87$ & $6.07 \pm 0.85$ & $<0.001$ \\
Backward & $2.75 \pm 0.88$ & $3.96 \pm 0.88$ & $<0.001$ \\
Trail-making test & & & \\
Form A time & $118.54 \pm 60.50$ & $66.54 \pm 36.31$ & 0.001 \\
Form A false & $1.19 \pm 1.78$ & $0.11 \pm 0.41$ & 0.004 \\
Form B time & $271.18 \pm 142.38$ & $141.93 \pm 79.15$ & $<0.001$ \\
Form B false & $2.73 \pm 3.05$ & $0.5 \pm 1.03$ & $<0.001$ \\
A + B time & $381.73 \pm 197.94$ & $208.5 \pm 115.23$ & 0.001 \\
A - B time & $160.64 \pm 94.42$ & $75 \pm 43.81$ & 0.001 \\
A/B time & $2.58 \pm 0.87$ & $2.11 \pm 0.18$ & $<0.001$ \\
Clock-drawing test & 3.1 & 3.96 & $<0.001$ \\
\hline
\end{tabular}

Values are means \pm standard deviations. Significant at $p<0.05$.

temporal disorientation have been shown in patients with bilateral medial thalamic infarction (Percheron artery infarction) [23]. Ghika-Schmid and Bogousslavsky [24] showed that patients with tuberothalamic artery infarction had disturbances in attention, memory, and orientation. In our study, in the digit span tests used for evaluating attention, the anteromedial group had the lowest score in both forward and backward digit span. Additionally, in the attention and orientation subgroups of the MMSE, the anteromedial group also obtained the lowest score. These results are consistent with the former results that anteromedial thalamic involvement impairs attention and orientation.

Impairment of memory has been reported in patients with an anteromedial lesion on the thalamus [23, 24]. Also, patients with lateral posterior choroidal artery ischemia and memory impairment have been reported [25]. In our study, the anteromedial group had the lowest scores on immediate memory and best learning in the verbal memory process test. Simultaneously, the posterolateral group's failure in the delayed recall and total recall subgroups was noted. The posterolateral group also had the lowest score in the recall subgroup of the MMSE. These results showed that patients with posterolateral lesions failed to record information. The low scores of the 
Table 3. Results of the neuropsychological tests according to lesion localizations

\begin{tabular}{|c|c|c|c|c|}
\hline Tests & Anteromedial & Anterolateral & Posterolateral & Dorsal \\
\hline \multicolumn{5}{|c|}{ Mini-Mental State Examination } \\
\hline Orientation & $8 \pm 1$ & $8.47 \pm 2.13$ & $9.2 \pm 0.83$ & $9.4 \pm 0.89$ \\
\hline Attention/calculation & $1.33 \pm 0.57$ & $2.53 \pm 2.06$ & $2.6 \pm 2.07$ & $1.60 \pm 1.51$ \\
\hline Recall & $1.33 \pm 1.52$ & $1.67 \pm 0.9$ & $1 \pm 1$ & $1.20 \pm 1.3$ \\
\hline Language & $7.33 \pm 0.57$ & $6.73 \pm 2.82$ & $8 \pm 1.41$ & $7.60 \pm 1.51$ \\
\hline \multicolumn{5}{|l|}{ Verbal memory process test } \\
\hline Immediate memory & $5.33 \pm 2.51$ & $8.2 \pm 3.16$ & $6.6 \pm 2.3$ & $7.4 \pm 1.51$ \\
\hline Best learning & $6.67 \pm 3.05$ & $8.73 \pm 1.58$ & $7.6 \pm 2.30$ & $8.6 \pm 1.14$ \\
\hline Delayed recall & $2.33 \pm 3.21$ & $6.13 \pm 3.48$ & $2.8 \pm 4.20$ & $5.40 \pm 2.70$ \\
\hline Total recall & $8.33 \pm 2.51$ & $10.73 \pm 4.04$ & $7.6 \pm 4.03$ & $11.20 \pm 2.95$ \\
\hline \multicolumn{5}{|l|}{ Verbal fluency test } \\
\hline Phonemic & $4 \pm 4.35$ & $6.20 \pm 4.48$ & $7.8 \pm 5.32$ & $8.6 \pm 3.57$ \\
\hline Semantic & $7 \pm 5.19$ & $13.33 \pm 4.48$ & $11.4 \pm 5.12$ & $11 \pm 2.91$ \\
\hline \multicolumn{5}{|l|}{ Digit span test, mean \pm SD } \\
\hline Forward & $4.33 \pm 0.57$ & $4.6 \pm 0.98$ & $4.6 \pm 0.89$ & $4.6 \pm 0.89$ \\
\hline Back & $2.33 \pm 0.57$ & $2.73 \pm 0.96$ & $3 \pm 1.22$ & $2.8 \pm 0.44$ \\
\hline \multicolumn{5}{|l|}{ Trail-making test } \\
\hline Form A time & $202.65 \pm 45.35$ & $102.08 \pm 60.60$ & $111.80 \pm 48.87$ & $117.60 \pm 46.89$ \\
\hline Form A false & $3.33 \pm 1.75$ & $1.08 \pm 1.75$ & $1 \pm 2.23$ & $0.40 \pm 0.54$ \\
\hline Form B time & $480 \pm 12$ & $220.73 \pm 143.19$ & $215.33 \pm 4.37$ & $290.40 \pm 108.50$ \\
\hline Form B false & $7 \pm 2.64$ & $2.55 \pm 3.11$ & $2 \pm 2$ & $1 \pm 1.22$ \\
\hline $\mathrm{A}+\mathrm{B}$ time & $682.67 \pm 44.55$ & $308.64 \pm 190.69$ & $305 \pm 80.01$ & $408 \pm 150.71$ \\
\hline A - B time & $277.33 \pm 49.16$ & $132.82 \pm 101.15$ & $126.67 \pm 51.86$ & $172.8 \pm 72.33$ \\
\hline $\mathrm{A} / \mathrm{B}$ time & $2.43 \pm 0.52$ & $2.57 \pm 0.97$ & $2.84 \pm 1.26$ & $2.54 \pm 0.79$ \\
\hline Clock-drawing test & 1.66 & 3.2 & 3 & 3.8 \\
\hline
\end{tabular}

Values are means \pm standard deviations. Those that differ significantly from the others are written in bold.

anteromedial group on immediate memory and best learning were attributed to the disturbance of attention as well as memory impairment.

A decrease in verbal and nonverbal fluency has been observed in patients with anterior thalamic lesions [24]. In another case, verbal fluency impairment without aphasia has been shown in a patient with an infarction in the left thalamus's polar region [4]. Also, 2 aphasic patients with impaired speech fluency, comprehension, and naming resulting from lateral thalamic ischemia have been presented before [10]. In this study, the anteromedial group obtained the lowest score in both the semantic and phonemic subgroups of verbal fluency tests performed to evaluate continuous attention, persistence, and language. Interestingly, the anterolateral group achieved the highest semantic fluency score, although it obtained a low score in phonemic fluency. In the language subgroup of the MMSE, the lowest mean belonged to the anterolateral group. These results suggest that besides the anteromedial region, the anterolateral region of the thalamus may also be associated with language. In patients with antero- medial hemorrhage, it is thought that there might be impairment in language, perseverance, and sustained attention skills due to the lowest scores in both fluency tests.

It has been reported that planning, sequencing, construction, and executive functions may be impaired in patients with anteromedial lesions of the thalamus [4, 24, 26]. In our study, both in the trail-making test performed to assess executive functions and in the clock-drawing test performed to evaluate planning, sequencing, and construction skills, the worst scores were obtained by the anteromedial group. In contrast, the scores of the other groups were very close to each other. This result suggests that the anteromedial regions of the thalamus may be associated with all these skills.

In our study, depression scales were found to be higher in the posterolateral and anterolateral groups. It was observed that patients with moderate/severe depressive characteristics were especially those with mild motor deficits. It could not be determined whether this result was due to any thalamic nucleus involvement because of the insufficient number of patients. 
Several limitations of the current study need to be discussed. Although the global and the subdomains' cognitive impairment of patients with thalamic hemorrhage was evaluated according to lesion localization and the results were compared with those of healthy individuals, the patients' cognitive status before hemorrhage was not confirmed by standard neuropsychological tests. Additionally, the relatively small sample size is a shortcoming of the present study.

It was concluded in this study that thalamic hemorrhages affect cognition entirely regardless of the localization of the lesion. It was also observed that the lateral part of the thalamus was associated with language, the posterior part with memory, and the anteromedial part with the rest of the cognitive subdomains. This study is valuable since it is the first study evaluating the detailed cognitive status of patients with thalamic hemorrhage regarding lesion localization. Future longitudinal studies with larger samples are needed to verify these results.

\section{Statement of Ethics}

Local Ethics Committee approval from Gulhane Training and Research Hospital was obtained (Reference No. 19/233). Informed consent was obtained from the patients.

\section{Conflict of Interest Statement}

The authors have no conflicts of interest to declare that are relevant to the content of this article.

\section{Funding Sources}

No funding was received for conducting this study.

\section{Author Contributions}

M.T.: conceptualization, data curation, formal analysis, visualization, methodology. B.S.A.P.: methodology, supervision, visualization, writing - review and editing. N.K.: conceptualization, data curation, formal analysis, visualization. O.K.: visualization, writing - review and editing.

\section{References}

1 Herrero MT, Barcia C, Navarro JM. Functional anatomy of thalamus and basal ganglia. Childs Nerv Syst. 2002 Aug;18(8):386-404.

2 Ropper AH, Samuels MA, Klein JP, Prasad S. Adams and Victor's Principles of Neurology. 11th ed. New York: McGraw-Hill Education; 2019.

3 Daroff R. Bradley's Neurology in Clinical Practice. 7th ed. Elsevier; 2015.

4 Clarke S, Assal G, Bogousslavsky J, Regli F, Townsend DW, Leenders KL, et al. Pure amnesia after unilateral left polar thalamic infarct: topographic and sequential neuropsychological and metabolic (PET) correlations. JNeurol Neurosurg Psychiatry. 1994 Jan;57(1): 27-34.

5 Castaigne P, Lhermitte F, Buge A, Escourolle R, Hauw JJ, Lyon-Caen O. Paramedian thalamic and midbrain infarct: clinical and neuropathological study. Ann Neurol. 1981 Aug;10(2):127-48.

6 Guberman A, Stuss D. The syndrome of bilateral paramedian thalamic infarction. Neurology. 1983 May;33(5):540-6.

7 Bogousslavsky J, Regli F, Assal G. The syndrome of unilateral tuberothalamic artery territory infarction. Stroke. 1986 May-Jun; 17(3):434-41.

8 Graff-Radford NR, Eslinger PJ, Damasio AR, Yamada T. Nonhemorrhagic infarction of the thalamus: behavioral, anatomic, and physiologic correlates. Neurology. 1984 Jan;34(1): $14-23$.

9 Graff-Radford NR, Tranel D, Van Hoesen GW, Brandt JP. Diencephalic amnesia. Brain. 1990 Feb;113(Pt 1):1-25.

To Determine the Cognitive Subgroup Associated with the Thalamus
10 Karussis D, Leker RR, Abramsky O. Cognitive dysfunction following thalamic stroke: a study of 16 cases and review of the literature. J Neurol Sci. 2000 Jan;172(1):25-9.

11 Caplan LR, DeWitt LD, Pessin MS, Gorelick PB, Adelman LS. Lateral thalamic infarcts. Arch Neurol. 1988 Sep;45(9):959-64.

12 Fama R, Sullivan EV. Thalamic structures and associated cognitive functions: Relations with age and aging. Neurosci Biobehav Rev. 2015 Jul;54:29-37.

13 Güngen C, Ertan T, Eker E, Yaşar R. [Reliability and validity of the standardized Mini Mental State Examination in the diagnosis of mild dementia in Turkish population]. Turk Psikiyatri Derg Winter. 2002;13(4):273-81.

14 Öktem Ö. Sözel bellek süreçleri testi (SBST): bir ön çalışma. Noro Psikiyatri Arsivi. 1992;29(4):196-216.

15 Elwood RW. The Wechsler Memory Scale Revised: Psychometric Characteristics and Clinical Application. Neuropsychol Rev. 1991;2(2):179-201.

16 Mesulam MM, Gürvit IH. Davranıssal ve Kognitif Nörolojinin İlkeleri. Yelkovan Yayıncilık; 2004

17 Türkeş PN, Can PH, Kurt PM, Banu P, Dİkeç E. İz Sürme Testi' nin 20-49 Yaş Aralığında Türkiye İçin Norm Belirleme Çalıșması. Türk Psikiyatri Dergisi. 2015;26(3):189-196.

18 Deutsch Lezak M. Neuropsychological Assessment. 3rd ed. Oxford: Oxford University Press; 1995.
19 Ertan T, Eker E. Reliability, validity, and factor structure of the geriatric depression scale in Turkish elderly: are there different factor structures for different cultures? Int Psychogeriatr. 2000 Jun;12(2):163-72.

20 Ulusoy M, Sahin NH, Erkmen H. Turkish Version of the Beck Anxiety Inventory: psychometric Properties. J Cogn Psychother. 1998;12(2):163-72.

21 De Witte L, Brouns R, Kavadias D, Engelborghs S, De Deyn PP, Mariën P. Cognitive, affective and behavioural disturbances following vascular thalamic lesions: a review. Cortex. 2011 Mar;47(3):273-319.

22 Van Der Werf YD, Tisserand DJ, Visser PJ, Hofman PA, Vuurman E, Uylings HB, et al. Thalamic volume predicts performance on tests of cognitive speed and decreases in healthy aging. A magnetic resonance imaging-based volumetric analysis. Brain Res Cogn Brain Res. 2001 Jun;11(3):377-85.

23 Spiegel EA, Wycis HT, Orchinik C, Freed H. Thalamic chronotaraxis. Am J Psychiatry. 1956 Aug;113(2):97-105.

24 Ghika-Schmid F, Bogousslavsky J. The acute behavioral syndrome of anterior thalamic infarction: a prospective study of 12 cases. Ann Neurol. 2000 Aug;48(2):220-7.

25 Neau JP, Bogousslavsky J. The syndrome of posterior choroidal artery territory infarction. Ann Neurol. 1996 Jun;39(6):779-88.

26 Spiro HM. A contribution to the debate. Adv Mind Body Med. 2000;16(1):26-7. 